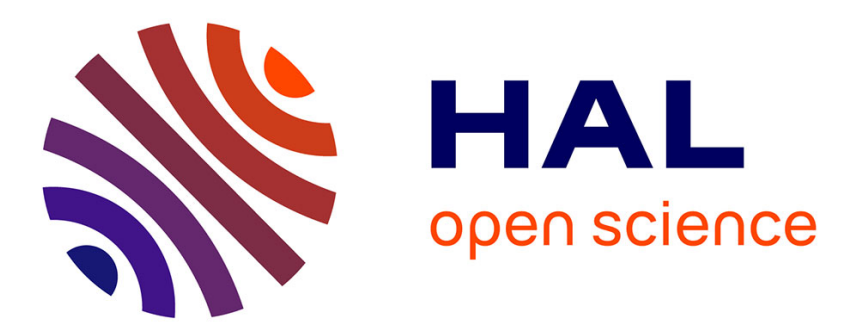

\title{
Mössbauer study of the crystallogenesis of iron hydroxides
}

\author{
Lj. Nalovic, Chr. Janot
}

\section{To cite this version:}

Lj. Nalovic, Chr. Janot. Mössbauer study of the crystallogenesis of iron hydroxides. Revue de Physique Appliquée, 1979, 14 (3), pp.475-480. 10.1051/rphysap:01979001403047500 . jpa-00244617

\section{HAL Id: jpa-00244617 https://hal.science/jpa-00244617}

Submitted on 1 Jan 1979

HAL is a multi-disciplinary open access archive for the deposit and dissemination of scientific research documents, whether they are published or not. The documents may come from teaching and research institutions in France or abroad, or from public or private research centers.
L'archive ouverte pluridisciplinaire HAL, est destinée au dépôt et à la diffusion de documents scientifiques de niveau recherche, publiés ou non, émanant des établissements d'enseignement et de recherche français ou étrangers, des laboratoires publics ou privés. 


\title{
Mössbauer study of the crystallogenesis of iron hydroxides
}

\author{
Lj. Nalovic \\ Centre O.R.S.T.O.M., B.P. 165, 97301 Cayenne Cedex, France \\ and Chr. Janot \\ Laboratoire de Physique du Solide, Faculté des Sciences, \\ C.O. no 140,54037 Nancy Cedex, France.
}

(Reçu le 12 mai 1978, révisé le 15 novembre 1978, accepté le 20 novembre 1978)

\begin{abstract}
Résumé. - Certains aspects de la pédogenèse des composés du fer dans le sol ont été simulés en étudiant l'influence de la disponibilité en ions $\mathrm{OH}$, du lessivage par l'eau et de la substitution isomorphique du fer par des éléments de transition sur la cristallogenèse des hydroxydes du fer. A partir des résultats obtenus par spectroscopie Mössbauer, il a été possible de montrer qu'une forte disponibilité en $\mathrm{OH}$ et, dans une certaine mesure, la présence d'impuretés de transition favorise l'apparition d'oxydes au détriment des hydroxydes. Par ailleurs, la cristallisation des composés est gênée par les impuretés substitutionnelles mais favorisée par un abondant lessivage.
\end{abstract}

\begin{abstract}
Pedogenesis of iron compounds in solids have been simulated by studying the influence of $\mathrm{OH}$ availability, water leaching and isomorphic substitution of iron by transitional elements on the crystallogenesis of iron hydroxides. The Mössbauer spectroscopy has shown that the appearance of oxide compounds instead of hydroxide is favoured both by high $\mathrm{OH}$ availability and, to some extend, by the presence of substitutional impurities. On the other hand, crystallization, which appeared as difficult when transition elements were present, was made easier by water leaching.
\end{abstract}

1. Introduction. - It has been long suspected that geochemical and crystallochemical aspects of the pedogenesis of iron compounds in soils can be deeply affected by factors such as :

- changes in the $\mathrm{pH}$ values or, more exactly, changes in the molecular ratio $D(\mathrm{OH})=[\mathrm{OH}] /[\mathrm{Fe}]$ (referred to as $\mathrm{OH}$ availability in the following), where $[\mathrm{OH}]$ is the total concentration of $\mathrm{OH}$ and not only the concentration of free $\mathrm{OH}^{-}$;

- isomorphic substitution of iron by transitional elements $\left(\mathrm{Mn}^{2+}, \mathrm{Cr}^{3+}, \mathrm{V}^{3+}, \mathrm{Co}^{2+}, \mathrm{Ni}^{2+}\right.$ or $\left.\mathrm{Cu}^{2+}\right)$;

- desionization of generated hydroxides under water leaching.

We actually know $[1,2]$ that $D(\mathrm{OH})$ values of about 2.0-2.5 (measured pH $=2.1-3.0$ ) ensures formation of a compound called hydroxide- $\mathrm{H}$ which exclusively generates $\mathrm{FeOOH}$-like oxihydroxides. In the case of adequate $D(\mathrm{OH})$ values (say $>3.0$ ) (measured $\mathrm{pH}=4.5-7.0$ ) the formation of hydroxide- $\mathrm{O}$ is ensured, which generates exclusively $\mathrm{Fe}_{2} \mathrm{O}_{3}$-like oxides. However, even though the fundamental role of $D(\mathrm{OH})$ in the direction of iron hydroxides crystallogenesis has been established, it has not been possible before to investigate samples of hydroxides generated at different $D(\mathrm{OH})$ values because of the very small size of some of their elementary particles. The same problem was encountered for soil studies [3].

Likewise the global influence of transitional trace elements on the crystallogenesis of ferric hydroxide has been previously studied [1]. Then, using the Mössbauer spectroscopy, it has been shown that these elements really replace iron atoms inside the primary crystalline organization of hydroxide-O, significantly modifying its characteristics and crystallochemical outlines [4]. Consequently there could be a slowing down, if not a complete absence, of growth of elementary hydroxide micro-organizations which, during evolution, either appear in the form of superparamagnetic micro-crystals even at the liquid nitrogen temperature or stay amorphous in view of all classical methods [5].

So it will be the purpose of this paper to simulate the influence of the above factors on synthetically produced ferric iron hydroxides and oxides and to 
investigate them with the help of the Mössbauer spectroscopy which can :

- identify the nature of the iron compound through hyperfine parameter measurements,

- characterize the crystallization state and lead to the particle size distribution through the study of superparamagnetic behaviour at very low temperature (down to liquid helium temperature).

2. Description of the investigated samples. - The samples investigated in this work were prepared from percloric acid solutions having a high metal concentration $(0.1 \mathrm{Mol})$. In pure systems (A and $\mathrm{B}$ samples) as well as in mixed systems $\left(\mathrm{Fe}^{3+}+\Sigma \mathrm{M}^{n+}, \mathrm{C}\right.$ and $\mathrm{D}$ samples) $\mathrm{N}-\mathrm{NaOH}$, were added to reach $D(\mathrm{OH})=2.5$ in $A$ and $C$ samples, and $D(\mathrm{OH})>3.0$ in $B$ and $D$ samples.

The A and B samples do not contain trace elements except for those introduced by chemically pure reagents. They will be referred to as pure iron hydroxides. They will be compared to samples $\mathrm{C}$ and $\mathrm{D}$ which were prepared from ferric solutions containing :

$\mathrm{M}^{n+}=\mathrm{Cr}^{3+}, \mathrm{V}^{3+}, \mathrm{Mn}^{2+}, \mathrm{Co}^{2+}, \mathrm{Ni}^{2+}$ and $\mathrm{Cu}^{2+}$ ions [5].

The precipitated samples were separated from the residual solution by filtering, then dried at $60^{\circ} \mathrm{C}$ and ground to $100 \mu$. A part of the samples was leached by water at about $60^{\circ} \mathrm{C}$ with a Soxhlet extractor, until the complete elimination of ions such as $\mathrm{Na}^{+}$ and $\mathrm{ClO}_{4}^{-}$. Eight samples have been obtained corresponding to the notation set out in table I.

The mineralogical composition of these eight samples, obtained by X-ray diffraction, is also reviewed in table $I$. The eight samples investigated by Mössbauer spectroscopy were equally analyzed in relation to their metal element composition. These results can be found in table I too (an interrogative mark in the X-ray analysis column of table I merely indicates that identification of any diffraction pattern was impossible).

Table I. - Main sample characteristics.

\begin{tabular}{|c|c|c|c|}
\hline $\begin{array}{c}\text { Metals } \\
\text { in samples }\end{array}$ & $D(\mathrm{OH})$ & $\mathrm{pH}$ & Leaching \\
\hline - & - & - & - \\
\hline \multirow{2}{*}{$\mathrm{Fe}^{3+}$} & $<2.5$ & 3 & \\
\hline & $>3$ & 7 & $\begin{array}{l}\text { No } \\
\text { Yes }\end{array}$ \\
\hline \multirow{2}{*}{$\mathrm{Fe}^{3+}+\Sigma \mathrm{M}^{n+}$} & $<2.5$ & 3 & $\begin{array}{l}\text { No } \\
\text { Yes }\end{array}$ \\
\hline & $>3^{\circ}$ & 7 & \\
\hline
\end{tabular}

3. Mössbauer spectroscopy data. - Classical Mössbauer patterns were recorded in the transmission geometry at room temperature, liquid nitrogen temperature and between $4 \mathrm{~K}$ and $20 \mathrm{~K}$. From hyperfine parameters values, oxides and hydroxides were identified and an estimate of the particle size was obtained from the temperature of the superparamagnetism transition.

Spectra after annealing procedure (as explained elsewhere [6]), were taken when necessary to make sure of the chemical nature of the initial compounds.

For samples exhibiting very low temperature for the superparamagnetic transition, i.e. containing very small particles, liquid helium temperature spectra were recorded and analyzed in terms of continuous hyperfine field distribution [7]. In turn, this hyperfine field distribution was interpreted in a model [8] in which collective magnetic excitations are introduced to explain fluctuation of the magnetization $M$ (and hence of the hyperfine field $H$ ), around the easy direction $\Delta$, so that even under the so-called blocking temperature, a nucleus will experience a thermally averaged field given by :

$$
H(V, T)=H(\infty, T)\langle\cos \theta\rangle_{T}
$$

where $T$ is the temperature at which Mössbauer data are collected,

$V$ is the particle volume,

$\theta$ is the angle between the magnetization vector $M$ and the easy direction of magnetization $\Delta$.

Assuming uniaxial anisotropy, $\langle\cos \theta\rangle_{T}$ can be easily calculated, as previously shown [9], that is :

$$
\langle\cos \theta\rangle_{T}=\frac{1}{2 \sqrt{a}} \frac{1-\exp (-a)}{F(\sqrt{a})}
$$

in which

$$
F(\sqrt{a})=\exp (-a) \int_{0}^{\sqrt{a}} \exp \left(t^{2}\right) \mathrm{d} t
$$

$\begin{array}{clc}\text { X-ray analysis } & \text { Notation } & \frac{\left[\mathrm{M}^{n+}\right]}{\left[\mathrm{Fe}^{3+}\right]} \\ - & - & - \\ ? & \text { A-NL } & 0.05 \\ \alpha-\mathrm{FeOOH} & \text { A-L } & 0.04 \\ ? & \text { B-NL } & 0.07 \\ \alpha-\mathrm{Fe}_{2} \mathrm{O}_{3} & \text { B-L } & 0.05 \\ ? & \text { C-NL } & 3.36 \\ \alpha-\mathrm{FeOOH}+\alpha-\mathrm{Fe}_{2} \mathrm{O}_{3} & \text { C-L } & 2.91 \\ ? & \text { D-NL } & 7.54 \\ \alpha-\mathrm{Fe}_{2} \mathrm{O}_{3} & \text { D-L } & 3.74\end{array}$


and

$$
a=\frac{K V}{k_{\mathrm{B}} T} .
$$

$K$ is the anisotropy energy constant of the material which actually is strongly influenced by particle sizes, temperature, chemical structure, etc. In the following, $K$ will be considered as a true constant within the particle size distribution present in the sample studied here, that is $K=5 \times 10^{3} \mathrm{~J} \mathrm{~m}^{-3}$ for hydroxide compounds $[9,10]$ and $K=10^{5} \mathrm{~J} \mathrm{~m}^{-3}$ for oxide compounds [8] which are experimental values for small particles of comparable size and as measured at low temperature (between 4 and $10 \mathrm{~K}$ ). The presence of impurities in $\mathrm{C}$ and $\mathrm{D}$ samples may affect the value of $K$, but this is very difficult to be estimated and has not been taken into account.

In the assumption of spherical shaped particles of diameter $d\left(V=\frac{\pi d^{3}}{6}\right)$, a given value of $\mathrm{d}$ results in a particular value of the hyperfine field $H$ of the $P(H)$ distribution, with a weight depending on the probability $P(d)$ of having a particle of diameter $d$.

To calculate $P(d)$ from the equivalent $P(H)$ curve, a renormalization process must be undertaken to allow for the non-linear transformation of the coordinate axis from $H$ to $d$ as explained elsewhere [9]. Taking into account the uncertainty in $K$, the $P(d)$ curves may be shifted by about $20 \%$ each side of their mean position.

The Mössbauer spectra can be classified as the following :

1) Zeeman sextuplets even at room temperature, as typically shown in figure 1, corresponding to rather well crystallized states and which confirm X-ray data, that is the existence of hydroxide in sample $\mathrm{AL}$

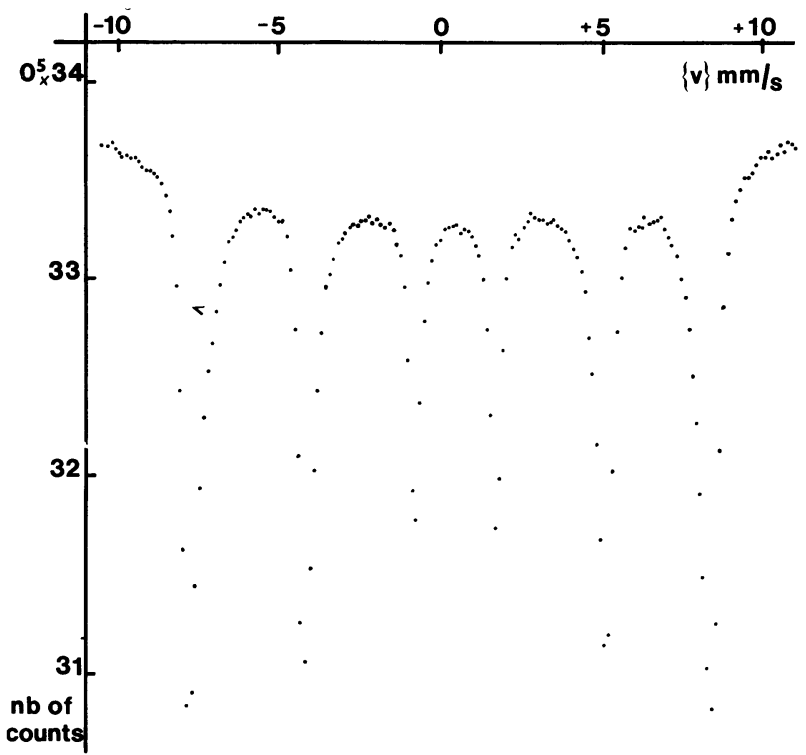

Fig. 1. - Typical Mössbauer spectrum recorded at room temperature from sample A-L.
$\left(H_{\mathrm{i}}=324 \mathrm{kOe} ; d>250 \AA\right)$, and of oxide in sample $\mathrm{BL}\left(H_{\mathrm{i}}=501 \mathrm{kOe} ; d>100 \AA\right)$.

2) Zeeman sextuplets plus superparamagnetic doublets at room temperature; only sextuplets at liquid nitrogen temperature, as typically shown in figure 2.

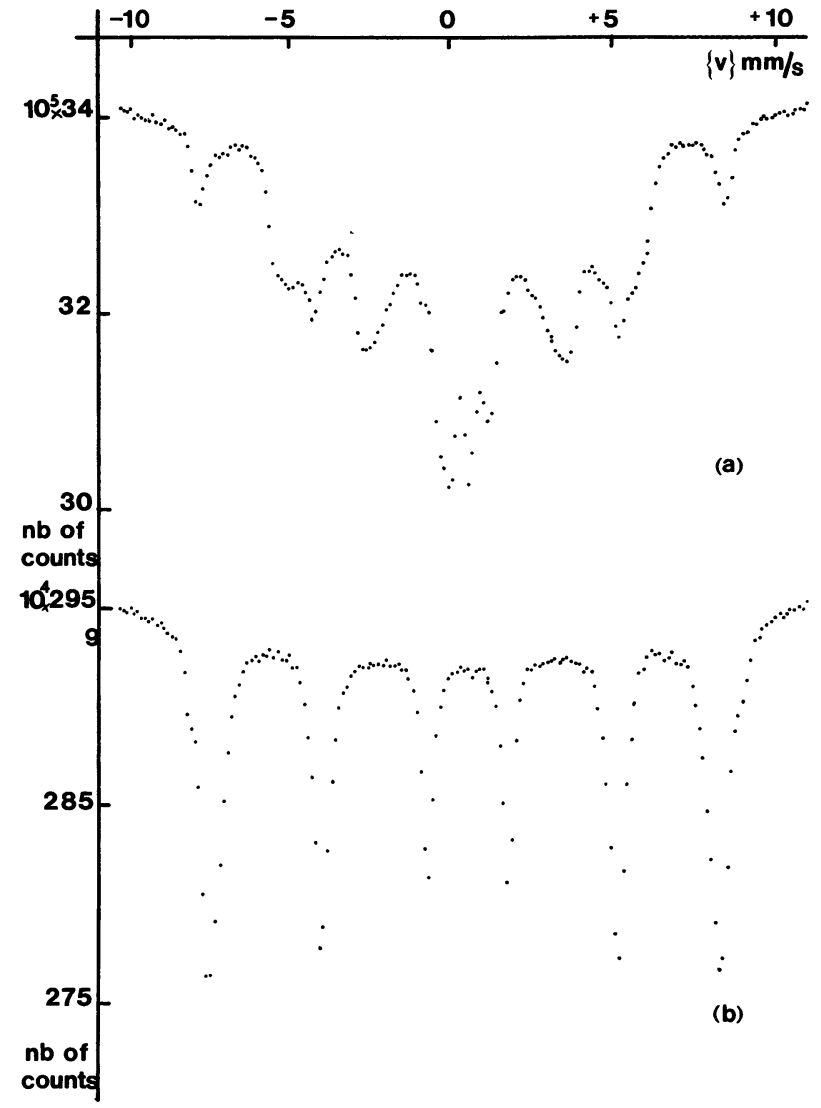

Fig. 2. - Typical Mössbauer patterns obtained from mixed and partially superparamagnetic compounds (CL or DL) : a) room temperature; $b$ ) liquid nitrogen temperature.

Again X-ray data are confirmed and made more accurate. Sample C-L appears as containing both well crystallyzed oxides $(20 \%)$ and superparamagnetic hydroxides $(80 \%)$, while sample D-L contains only oxides in a partially superparamagnetic state : $15 \%$ with $d(\AA)<40,25 \%$ with $40<d(\AA)<100$ and $60 \%$ in a fairly well crystallized state.

3) Zeeman sextuplets obtained only at very low temperature (below $20 \mathrm{~K}$ ), corresponding to very small particles in unleached samples A, B, C, D-NL, and which exhibit typical asymmetric aspects (see Fig. 3). They give hyperfine field distribution as shown in figure 4 , which can be transformed in particle size distribution $P(d)$ through the fast relaxation model as explained previously. Samples A-NL and C-NL are hydroxide-like materials while B-NL and D-NL appear as oxides. Particle size distributions are represented in figure 5 .

The main features of this Mössbauer analysis are summarized in table II. 


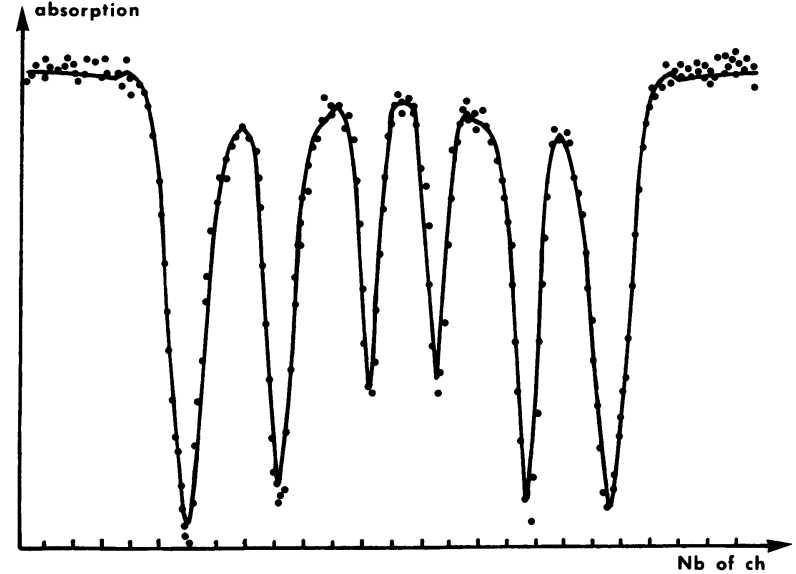

Fig. 3. - Mössbauer spectra obtained from NL samples at $4.2 \mathrm{~K}$.

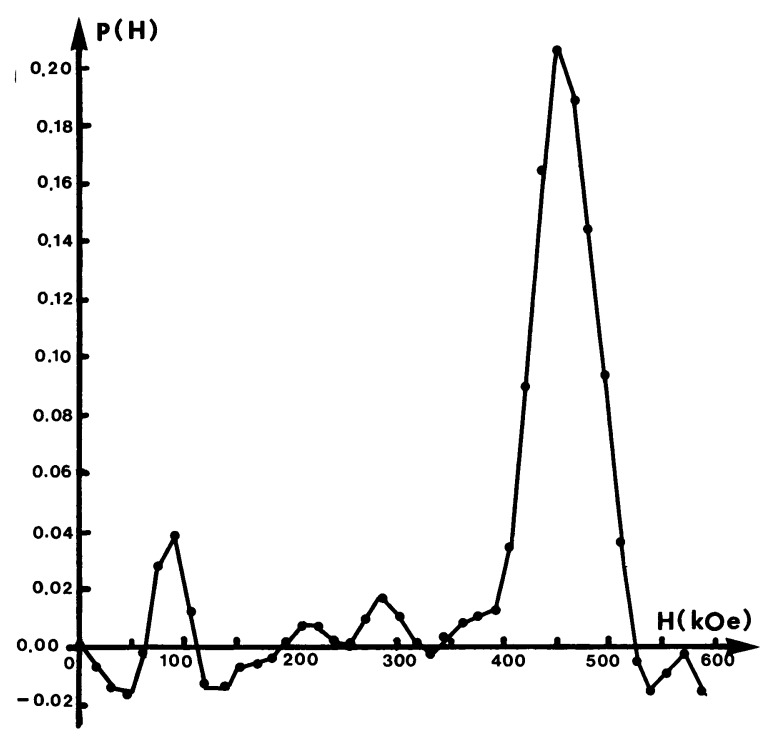

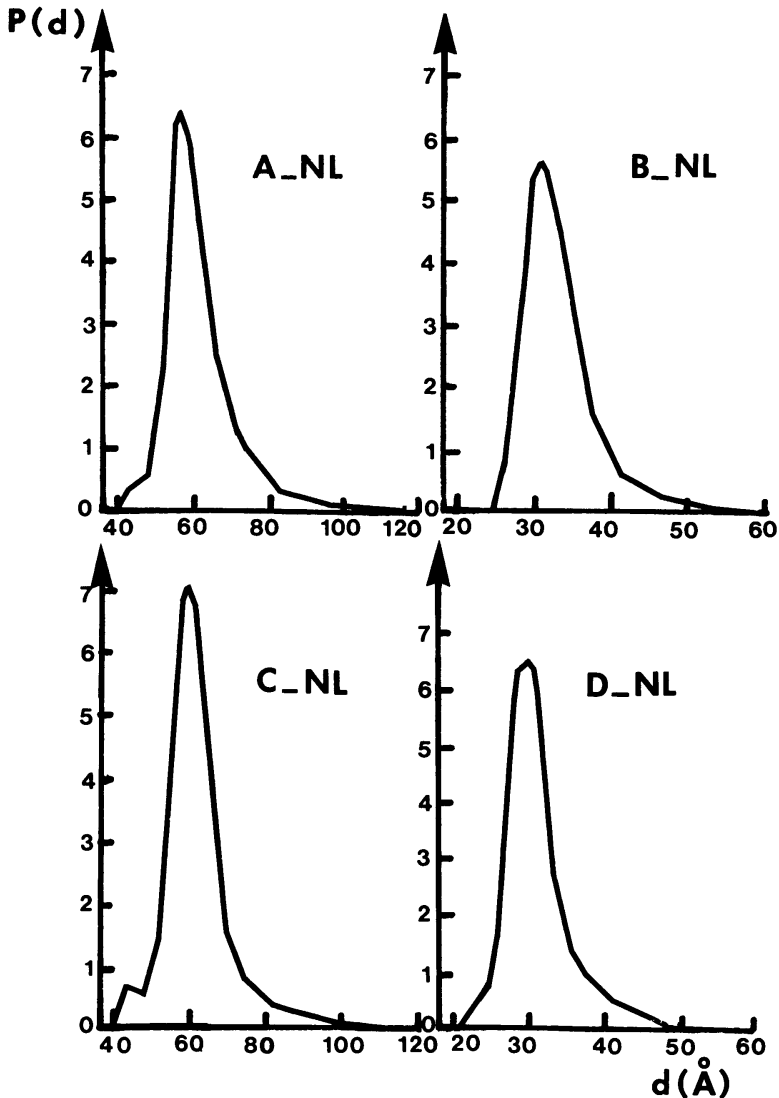

Fig. 5. - Particle size distribution as obtained from Mössbauer data (unleached samples).

Fig. 4. - Hyperfine field distribution as obtained from figure 3 spectrum.

Crystalline species

Particule size $\left(^{*}\right)$

Table II.
Samples<smiles>N#N</smiles>

$\mathrm{Fe}+\Sigma \mathrm{M}$

C-L
Mineralogical nature

hydroxide
oxihydroxide
oxide
oxide

hydroxide

oxihydroxide

D-NL

D-L

+
oxide
oxide
oxide

$\{60 \%-\bar{d}=40-60 \AA$ $\{0 \%-d=60-80 \AA$ $100 \%-d>250 \AA$

$\{83 \%-d=20-30 \AA$

$\{17 \%-d=30-40 \AA$ $100 \%-d>100 \AA$

$\{80 \%-d=40-60 \AA$

$\{20 \%-d=60-70 \AA$

$\{40 \%-d=90-250 \AA$

$\{40 \%-d>250 \AA$

$20 \%-d>100 \AA$

$\{55 \%-d=17-23 \AA$

$\left\{\begin{array}{l}45 \%-d=23-35 \AA\end{array}\right.$

$\int 15 \%-d<40 \AA$

$\{25 \%-d=40-100 \AA$

$60 \%-d>100 \AA$

${ }^{*}$ ) The accuracy on proportion of fractions can be estimated to be about $10 \%$. 
Particle size distribution might be obtained for A-L, B-L, C-L and D-L samples from the room temperature or the liquid nitrogen temperature spectra respectively as it is done for the NL samples at low temperature, although with a worse accuracy. Actually only lower limits or restricted range of the particle size are given as deduced from the blocking temperature being above room temperature or between liquid nitrogen and room temperature. Going further has not been judged worthwhile for the purpose of this study.

4. Interpretation of the results and conclusion. The results obtained by the Mössbauer spectroscopy and presented in this paper may be considered as interesting from several points of view :

4.1 The CRYSTALline ORganization OF THE IRON COMPOUNDS. - As already been put out into doubt [4, 11] there is no evidence here for the existence of really amorphous compounds and all the samples seem to be made of typical oxides or hydroxides. Some of them are in so small particles that they should not gather more than ten iron atoms.

4.2 FORMATION CONDITIONS AND CRYSTALLOGENESIS. - The major role played by the $D(\mathrm{OH})$ value in the orientation of crystallogenesis is hereby confirmed. In fact when a limited quantity of $(\mathrm{OH})$ groups is available, for example $D(\mathrm{OH}) \simeq 2.0-2.5$, the iron atoms keep the water molecules in their closest neighbouring. If the iron atoms have to precipitate, under the effect of factors such as dehydration and concentration, they draw water molecules into the neoformed structure (hydroxide-H). In aqueous systems, the highly polarized water molecules, linked to the $\mathrm{Fe}$ ions, favorize linear polymerization : $\mathrm{Fe}-(\mathrm{OH})_{2}-$ $\mathrm{Fe}-(\mathrm{OH})_{2} \ldots$, whereas during precipitation they prevent the lateral agglomeration of iron hydroxopolynuclear chains into the tridimensional structure as it happens for an hydroxide-O which is typical of $D(\mathrm{OH})>3.0$. The difference in the manner of polymerizing could therefore explain the difference in the particle size as observed in non-leached samples (see table II). Anyway, crystallization is oriented towards oxide $\mathrm{Fe}_{2} \mathrm{O}_{3}$ or oxihydroxide $\mathrm{FeOOH}$ for $D$ $(\mathrm{OH})$ values $>3.0$ or around 2.0-2.5 respectively. On leaching, hydroxide- $\mathrm{H}$ loses its protons and the electro-positive charge decreases. Then, there is a rapid growth of elementary crystals from linear hydroxopolymers of iron by their lateral joining (side to side). For instance the transformation

$$
\mathrm{A}-\mathrm{NL}-d=40-80 \AA \stackrel{\text { leaching }}{\longrightarrow} \mathrm{A}-\mathrm{L}-d>250 \AA
$$

is more spectacular than that observed for hydroxide$\mathrm{O}$ :

$$
\text { B-NL }-d=20-40 \AA \stackrel{\text { leaching }}{\longrightarrow} \text { B-L }-d>100 \AA .
$$

The presence of transitional trace elements results in a decrease of the average particle size and in a broadening of the distribution, whatever the $D(\mathrm{OH})$ value is. On the other hand, oxihydroxide $\alpha-\mathrm{FeOOH}$ may be partially transformed into $\alpha-\mathrm{Fe}_{2} \mathrm{O}_{3}(20 \%$ in $\mathrm{C}-\mathrm{L}$ ) in the presence of transitional trace element if $D(\mathrm{OH})$ is in the range of low values $(2.0-2.5)$.

However, the oxide of sample $C$ is not perceptible with the Mössbauer spectroscopy, until after leaching and elimination of a part of $\Sigma \mathrm{M}$, even though it should be there, if reference is made to samples B-NL and D-NL where it has been found.

The action of leaching water (distilled) in the eventual transformation $\mathrm{FeOOH} \rightarrow \mathrm{Fe}_{2} \mathrm{O}_{3}$ must be discarded, after all our anterior results. Then we must admit that during titration of concentrated iron solutions, in the presence of $\Sigma M$ and for a low $R$ $\mathrm{Mol} \mathrm{OH} / \mathrm{Fe}+\Sigma M$, a hydroxide particularly heterogeneous forms. It is composed of fractions, different from the point of view of the $\mathrm{Fe}-\mathrm{M}$ substitution rate and of the $\mathrm{Fe}-\mathrm{OH}$ complexation degree (mixture of hydroxides- $\mathrm{H}$ and $-\mathrm{O}$ ). Yet the internal structure of these fractions must be sufficiently similar so that their differences escape our observation. In fact, it is only the elimination of a part of $\Sigma M$ which permits the tridimensional polymerization of a fraction of the sample and the appearence of oxide $\alpha-\mathrm{Fe}_{2} \mathrm{O}_{3}$.

In conclusion, this study, made with the help of the Mössbauer spectroscopy, on iron hydroxide and oxide samples synthetically obtained, has reached conclusions about their nature and properties. The fact that the conditions of the formation and evolution of the samples roughly represent those which exist in a natural environment [1] gives these conclusions a special intërest.

From a more general point of view, the results obtained here are also of interest because they refute the eventual existence, for the compounds studied, and thus for their natural homologues, of iron compounds that are really amorphous. They could possibly exist while the hydroxides are still within the original solutions (before dehydration) and where, precisely, the answer to many questions relative to the nature, characteristics and behaviour of iron compounds must be looked for in the future.

\section{References}

[1] Nalovic, Lj., Travaux et Documents O.R.S.T.O.M., $\mathrm{n}^{\circ} 66$ (1974), p. 235.

[2] Nalovic, Lj. and Pedro, G., C.R. Hebd. Séan. Acad. Sci., To be published in (1978).
[3] Kodama, H., McKeague, J. A., Tremblay, R. J., Gosselin, J. R. and Townsend, M. G., Can. J. Earth Sci. 14 (1977) $1-15$. 
[4] Nalovic, Lj., Pedro, G. and Janot, Chr., Proc. Int. Clay Conf. (Mexico) 1975, p. 601-610.

[5] Nalovic, Lj., C.R. Hebd. Séan. Acad. Sci. 273 (1971) 16641667.

[6] Janot, Chr., Gibert, H. and Tobias, Bull. Soc. Fr. Min. et Crist. 96 (1974), 281.

[7] Mangin, Ph., Marchal, G., Piecuch, M. and Janot, Chr., J. Phys. E. Sci. Int. 9 (1976) 1101.
[8] Mфrup, S. and Tops $\phi$ E, H., Appl. Phys. 11 (1976) 63.

[9] Williams, J.-M., Danson, D. P. and Janot, Chr., To be published in Physics in Medicine and Biology (1978) June issue.

[10] Hanžel, D., Sevsek, F., J. Physique Colloq. 37 (1976) C6-247.

[11] Gangas, N. H., Simopoulos, A., Kostikas, A., Yassoglou, N. J. and Filippakis, S., Clays and Clay Minerals 21 (1973) 151-160. 